\title{
Role of Elaborate Cardiotocography (CTG) in Pregnancy Management
}

\author{
Amena Khatun ${ }^{1}$, Nurun Nahar Khanam², Fahmida Nazir ${ }^{1}$ \\ ${ }^{1}$ Medical Officer, Department of Obstetrics and Gynaecology, BSMMU, ${ }^{2}$ Associate Professor, Department of Obstetrics and Gynaecology, BSMMU.
}

\begin{abstract}
:
Background: Elaborate Cardiotocography (CTG) is the most commonly used test for antepartum and intrapartum fetal surveillance because it gives information via the cerebro-cardiac response of fetal cerebral activity, which is modified by the hypoxia. Objective: This study was designed to compare the perinatal outcomes among the normal and abnormal CTG groups. Method: It was a prospective observational study carried out in the Department of obstetrics, BSMMU during the period July 2006 to July 2008. Hundred consecutive normal and hundred consecutive abnormal CTC tracings were collected from patients who were advised to perform CTG after admission. Both labour and non-labour patients were included. Interpretation of CTG was done based on FlGO recommendation (1987). Pregnancy and neonatal data were obtained and the findings were correlated with the FHR tracing. Statistical analysis was carried out by student's unpaired t-test, $\mathrm{X}^{2}$ and Z-test. Level of significance was set at P value $<0.05$. Results: Out of 100 abnormal CTG, 30\% had tachycardia, $42 \%$ had deceleration, 38\% was non reactive, $4 \%$ had absence beat-to-beat variability and $4 \%$ had fetal bradycardia. There was significantly higher caesarean delivery, lower apgar score, higher requirement of neonatal resuscitation and admission at neonatal unit and higher perinatal death among the abnormal CTG group. The abnormal fetal outcome was found highest in heart rate deceleration group. Conclusion: CTG can be continued as a good screening test of fetal surveillance but it is not the sole criteria to influence the management of high-risk pregnancies. Abnormal CTG should be supplemented with other test before intervention.
\end{abstract}

Key words: CTG, Perinatal outcome.

[BSMMU J 2009; 2(1): 18-24]

\section{Introduction:}

Cardiotocography (CTG) is the graphic presentation of fetal heart activity and the uterine contraction to detect the fetal hypoxia ${ }^{1}$. It is the most commonly used test for antepartum and intrapartum fetal surveillance in the majority hospitals of developed countries ${ }^{1}$. This technology was first developed in 1950 and became commercially available in $1960^{1}$. The goal of antepartum fetal surveillance is to predict, diagnose and timely intervene the pregnancies those are complicated with fetal asphyxia and might lead to fetal and newborn morbidity and death ${ }^{2}$.

The electronic FHR in all fetuses with asphyxia is expected to exhibit one or more heart rate pattern abnormalities. False negative rate of reactive Contraction stress test (CTG) is low, 3 per 1000, which is similar to that of $\mathrm{BPP}^{3}$. The negative predictive value is similar to that of BPP (99.5\% for NST, 98.5\% for BPP) but positive predictive value of an abnormal non stress test (NST) (37\%) is better than other screening tests ${ }^{3}$. Sensitivity of NST is $97 \%{ }^{3}$. In addition, electronic FHR monitoring is significantly

Address for correspondence: Dr. Amena Khatun, Medical Officer, Department of Obstetrics and Gynaecology, BSMMU, Dhaka, Bangladesh, E-mail address: himikabd@yahoo.com Contact: 01818258112 better in detecting all types of acidemia, metabolic (95.5\%), mixed (95\%) and respiratory $(100 \%)^{3}$.

Contraction stress test (CST) is one of the forms of fetal surveillance; it is still the only form that tries to use the principle of induced stress to reveal marginal placental insufficiency. But the procedure is risky due to chance of premature labour ${ }^{4}$.

Great efforts have been made to increase the reliability of the antepartum non stress test (NST) in order to detect fetal deterioration early ${ }^{5}$. Yet visual interpretation of FHR records is associated with a high inter and intra observer variability that greatly reduces its accuracy ${ }^{5}$. Classification system for electronic FHR monitoring tracing is capable of discriminating both healthy fetuses and those at risk for acidemia at birth and subsequent neonatal complication ${ }^{6}$.

From 70 to almost 90 percent fetal death occur before the onset of labour ${ }^{7}$. A large number of antepartum fetal deaths are caused by uteroplacental insufficiency ${ }^{8}$. Antepartum fetal testing by identifying the uteroplacental insufficiency and timely intervention has prevented many fetal deaths ${ }^{8}$. Similarly intrapartum fetal monitoring by detecting fetal distress in early stages has saved many fetuses from demise ${ }^{9}$. 
NST is less expensive, noninvasive, technically simpler and less time consuming and has a higher false positive and possibly lower false negative rate than BPP or $\mathrm{CST}^{7-10}$. It has surpassed oxytocin stress test due to its safety, convenience to the patient and the physician, non invasiveness, easy interpretation, can be repeated without risk ${ }^{7-10}$.

This study was designed to compare the pregnancy outcomes and early neonatal outcomes among the normal and abnormal CTG groups and to find out the association between abnormal findings of CTG with that of pregnancy outcomes and early neonatal outcomes.

\section{Methods:}

It was a prospective observational study carried out in the Department of Obstetrics and Gynaecology, BSMMU during the period, July 2006 to December 2007. Only indoor patients were included here.

One hundred consecutive normal and one hundred consecutive abnormal CTC tracings were collected from patients who were advised to perform CTG after admission to exclude fetal asphyxia. Both labour and non-labour patients were included. Patient having multiple pregnancy and pregnancy less than 32 weeks were excluded from the study. Inform consent was taken from the patients. All CTG was performed from the same CTC machine by the same obstetrician. Initially the monitoring was done for 20 minutes and if there was no fetal movement or heart rate acceleration within those 20 minutes then the monitoring was continued for another 20 minutes.

Interpretation of CTG was based on FlGO recommendation (1987). CTG was considered normal when the basal heart rate was $110-150 \mathrm{bpm}$, beat to beat variability was 5-25 bpm and at least two accelerations of the fetal heart rate were present during a 20 minutes period, each at least 15 beats above the baseline rate and lasting at least 15 seconds. Abnormal CTG included fetal tachycardia ( $>150 \mathrm{bpm})$, fetal bradycardia $(\mathrm{FHR}<110$ bpm), reduced or absent beat-to-beat variability, late decelerations and extreme variable decelerations.

Pregnancy outcomes and neonatal data were obtained from delivery note and neonatal chart review and the findings were correlated with the FHR tracing.

Measures of pregnancy outcomes were mode of delivery, indications of caesarean section, percentage requiring caesarean section for fetal distress, olygohydramnios, meconium stained liquor, small placenta, and cord around the neck or the fetus.

Measures of neonatal outcome were Apgar score at 1 and 5 minutes after birth, birth weight, requirement of admission into neonatal intensive care unit (NICU) for reasons other than pre-maturity, duration of stay in NICU, complications, perinatal mortality.

Statistical analysis was carried out by unpaired students ttest, Chi-square test and Z-test. Level of significance was considered significant when $\mathrm{P}$ value was 0.05 or less.

\section{Results}

The mean age of the patients were $26.7 \pm 4.9$ years ranging from 18 to 36 . The mean age, height, weight, socio economical status and occupation were almost similar among the patients of both normal and abnormal CTG group (Table I).

Table-I

Distribution of the patients by socio demographical characteristics

\begin{tabular}{lccc}
\hline Variables & $\begin{array}{c}\text { Abnormal CTG } \\
(\mathrm{n}=100) \\
\text { Mean } \pm \text { SD }\end{array}$ & $\begin{array}{c}\text { Normal CTG } \\
(\mathrm{n}=100)\end{array}$ & $\begin{array}{c}\text { P } \\
\text { value }\end{array}$ \\
\hline Age in years & $26.7 \pm 4.9$ & $26.7 \pm 4.9$ & $0.15^{\mathrm{NS}}$ \\
Height (cm) & $152.6 \pm 5.2$ & $153.1 \pm 3.6$ & $0.13^{\mathrm{NS}}$ \\
Weight (kg) & $63.5 \pm 5.4$ & $62.8 \pm 7.3$ & $0.583^{\mathrm{NS}}$ \\
Occupation & & & \\
Housewife & $72 \%$ & $80 \%$ & \\
Teacher & $12 \%$ & $6 \%$ & \\
Service holder & $10 \%$ & $14 \%$ & \\
Student & $6 \%$ & 0 & \\
Economical status & & $48 \%$ & \\
Poor & $52 \%$ & $62 \%$ & \\
Middle class & $38 \%$ & & \\
\hline
\end{tabular}

$\mathrm{NS}=\mathrm{P}>0.05$

Previous history of stillbirth and abortion were more among the pregnant women with abnormal CTG but the difference was not statistically significant.

Haemodynamic parameters and haemoglobin were similar in both normal and abnormal CTG group (Table II) however; blood sugar was higher among the patient with abnormal CTG $(\mathrm{p}<0.05)$.

Figure 1 shows the different indications of CTG. Highest number was less fetal movement (23.0\%), followed by pre-eclampsia (18.0\%), oligohydramnios (18.0\%), prolonged 1st stage of labour (12.0\%), postdated 
pregnancy (10.0\%), IUGR (9.0\%), GDM (8.0\%), PROM (7\%), chronic hypertension (7.0\%) and others were Rhve, HbsAg +ve, placenta previae, thalassemia, fibroid uterus, meconeum stained liquor, polyhydramnios, CPD, bad obstetric history, rubella infection, and congenital heart disease.

\section{Table-II}

Haemodynamics, hematocrit and blood sugar levels of the study patients $(n=100)$

\begin{tabular}{lccl}
\hline Parameters & $\begin{array}{c}\text { Abnormal } \\
\text { CTG }\end{array}$ & $\begin{array}{c}\text { Normal } \\
\text { CTG }\end{array}$ & p value \\
\hline Pulse/minute & $84.5 \pm 7.5$ & $81.4 \pm 5.9$ & $0.023^{*}$ \\
$\begin{array}{l}\text { Systolic Blood } \\
\text { Pressure (mmHg) }\end{array}$ & $123.9 \pm 18.3$ & $122.9 \pm 15.9$ & $0.771^{\mathrm{NS}}$ \\
$\begin{array}{l}\text { Diastolic Blood } \\
\text { Pressure (mmHg) }\end{array}$ & $81.8 \pm 15.2$ & $79.4 \pm 12.4$ & $0.389^{\mathrm{NS}}$ \\
Haemoglobin (gm \%) & $10.0 \pm 1.7$ & $10.2 \pm 1.3$ & $0.503^{\mathrm{NS}}$ \\
Blood Sugar (mmol /l) & $6.9 \pm 1.8$ & $6.2 \pm 1.0$ & $0.021^{*}$ \\
\hline
\end{tabular}

NS $=\mathrm{P}>0.05$

* $=\mathrm{P}<0.05$

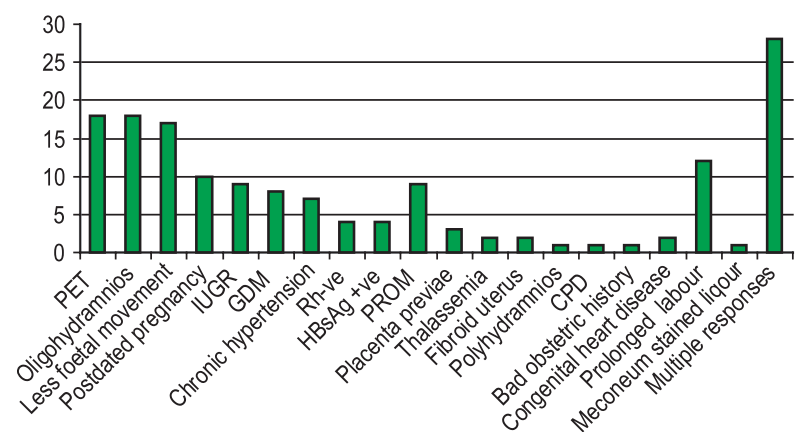

Fig. 1: Indications of CTG

Table-III shows the CTG abnormalities of the studied women. Out of 100 abnormal CTG 30\% had fetal tachycardia, 38\% had deceleration, 38\% was non reactive CTG, $4 \%$ had fetal bradycardia and $4 \%$ had absence beatto-beat variability. 18 patients had more than one abnormal findings.

Pregnancy outcome with abnormal CTG is shown in TableIV. It was found that out of 100 pregnant women, two fetuses were stillbirth and two died at $2^{\text {nd }}$ and two at $3^{\text {rd }}$ day of birth (perinatal death), all these six had deceleration in CTG (Table VII). Other abnormal outcomes were low apgar score at 1 minute and 5 minute, the babies needed immediate resuscitation and admission at neonatal care unit. All these parameters were higher in the abnormal

\section{Table-III}

Frequency distribution of major CTG abnormality of the patients $(n=100)$

\begin{tabular}{lcc}
\hline Types of abnormal CTG & Frequency & Percent \\
\hline Tachycardia & 30 & 30.0 \\
Bradycardia & 4 & 4.0 \\
Absent/reduced beat to beat variability & 4 & 4.0 \\
Deceleration & 38 & 38.0 \\
Non reactive & 38 & 38.0 \\
\hline
\end{tabular}

Table-IV

Distribution of the patients by pregnancy outcome in abnormal CTG group $(n=100)$

\begin{tabular}{lcc}
\hline $\begin{array}{l}\text { Types of abnormal } \\
\text { CTG }\end{array}$ & $\begin{array}{c}\text { Normal } \\
\text { outcome }\end{array}$ & $\begin{array}{c}\text { Abnormal } \\
\text { outcome }\end{array}$ \\
\hline Tachycardia $(\mathrm{n}=30)$ & $26(86.7 \%)$ & $4(13.3 \%)$ \\
Bradycardia $(\mathrm{n}=4)$ & $4(100 \%)$ & $0(0.0)$ \\
Absent beat to beat & $2(50.0 \%)$ & $2(50.0 \%)$ \\
variability (n=4) & & \\
Deceleration $(\mathrm{n}=38)$ & $6(15.8)$ & $32(84.2 \%)$ \\
Non reactive $(\mathrm{n}=38)$ & $10(52.6 \%)$ & $9(47.3 \%)$ \\
\hline Total $(\mathrm{n}=100)$ & $46(46 \%)$ & $54(54 \%)$ \\
\hline
\end{tabular}

Table-V

Distribution of the patients by delivery related variables

Variables Study subjects p value Abnormal CTG Normal CTG $(n=100) \quad(n=100)$ Frequency Frequency

Mode of delivery

LUCS

NVD

82

18

22

$0.001^{* *}$

Liquor amount

Almost nil 12

Less amount

Adequate

30

56

0

$0.091^{\mathrm{NS}}$

Polyhydramnios

Liquor colour

Normal

2

74

0

Meconeum stained

60

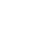

Umbilical cord

Normal

Compressed

40

86

$0.003^{* *}$

Placenta

Normal

Big

94

6

100

$0.242^{\text {NS }}$

Small

84
6
10

96

0.046*

$* *=\mathrm{P}<0.01$

$\mathrm{NS}=\mathrm{P}>0.05$

$*=\mathrm{P}<0.05$ 
CTG group. The abnormal fetal outcome was found to be highest in heart rate deceleration group followed by absence beat to beat variability and then non reactive CTG and lastly tachycardia group, the percentage were $76 \%$, $50 \%, 47 \%$ and $13 \%$ respectively. Pregnancy outcome was abnormal in only $4 \%$ of normal CTG group.

Caesarian delivery and meconium staining liquor was significantly higher in abnormal CTG group ( $\mathrm{p}<0.001)$. It was also revealed that the proportion of adequate amount of liquor was higher among the women with normal CTG (74.0.0\%) compared to abnormal CTG (56.0\%), but the difference was not statistically significant ( $p>0.05)$. Similarly the proportion of normal placenta was significantly high among the women with normal CTG
(96.0\%) compared to abnormal CTG (84.0\%). However, a statistically significant difference was found $(\mathrm{p}<0.05)$ in colour of liquor indicating the proportion of meconeum stained liquor was higher among the women with abnormal CTG (40.0\%) compared to normal CTG (14.0\%). No statistically significant difference was found in umbilical cord compression $(\mathrm{p}>0.05)$ though the compressed umbilical cord was found to be high among the women with abnormal CTG (Table V).

Fetal birth weight and apgar score at 1 minute and 5 minute was significantly lower in abnormal CTG group. The babies needed immediate resuscitation and admission at neonatal care unit was higher in this group (Table-VI). The fetal death rate was high among the women with abnormal CTG.

Table-VI

Distribution of the patients by fetal outcome

\begin{tabular}{llcc}
\hline Variables & \multicolumn{2}{c}{ Study subjects } & p value \\
\cline { 2 - 3 } & \multicolumn{1}{c}{$\begin{array}{c}\text { Abnormal CTG } \\
(\mathrm{n}=100)\end{array}$} & $\begin{array}{c}\text { Normal CTG } \\
(\mathrm{n}=100)\end{array}$ & $0.036^{*}$ \\
\hline Birth weight (kg) & $2.4 \pm 0.8(1.2-4.0)$ & $2.7 \pm 0.6(1.4-4.8)$ & $0.003^{* *}$ \\
Apgar score (1 minute) & $6.2 \pm 1.5(0-9)$ & $7.0 \pm 0.9(5-10)$ & $0.014^{*}$ \\
Apgar score (5 minute) & $8.6 \pm 1.6(0-10)$ & $9.3 \pm 1.2(2-10)$ & $0.021^{*}$ \\
Immediate resuscitation needed & $76 \%$ & $54 \%$ & $0.001^{* *}$ \\
Admission into neonatal care unit & $42 \%$ & $10 \%$ & 0.06 \\
\hline
\end{tabular}

Data expressed as mean \pm SD and percent. Figures in parenthesis indicate range.

$* *=\mathrm{P}<0.01$

Table-VII

Evaluation of perinatal death in different cases (medical audit)

\begin{tabular}{|c|c|c|c|c|c|c|}
\hline Sl. No. & Outcome & $\begin{array}{l}\text { Ges. } \\
\text { age }\end{array}$ & $\begin{array}{l}\text { Maternal risk } \\
\text { factors }\end{array}$ & CTG & $\begin{array}{l}\text { Mode of } \\
\text { delivery }\end{array}$ & $\begin{array}{l}\text { Cause of } \\
\text { death }\end{array}$ \\
\hline 1 & Stillbirth & 36 & Severe jaundice & $\begin{array}{l}\text { Non reactive } \\
\text { Deceleration } \\
\text { present }\end{array}$ & $\begin{array}{l}\text { Vaginal } \\
\text { delivery }\end{array}$ & $\begin{array}{l}\text { Birth weight } 2.5 \mathrm{~kg} \\
\text { Birth asphyxia }\end{array}$ \\
\hline 2 & Stillbirth & 34 & $\begin{array}{l}\text { Oligohydramnios } \\
\text { with severe } \\
\text { preeclampsia }\end{array}$ & $\begin{array}{l}\text { Non reactive } \\
\text { Deceleration } \\
\text { present }\end{array}$ & LUCS & $\begin{array}{l}\text { Birth weight } \\
1.8 \text { kgAntepartum } \\
\text { asphyxia }\end{array}$ \\
\hline 3 & $\begin{array}{l}\text { Neonatal } \\
\text { death at } \\
2^{\text {nd }} \text { day }\end{array}$ & 33 & $\begin{array}{l}\text { Pre eclampsia } \\
\text { with GDM } \\
\text { with IUGR }\end{array}$ & $\begin{array}{l}\text { Non reactive } \\
\text { Deceleration } \\
\text { present }\end{array}$ & LUCS & $\begin{array}{l}\text { Birth weight } \\
1.4 \mathrm{~kg} \text {, SGA } \\
\text { with prematurity }\end{array}$ \\
\hline 4 & $\begin{array}{l}\text { Neonatal } \\
\text { death at } \\
2^{\text {nd }} \text { day }\end{array}$ & 33 & $\begin{array}{l}\text { Oligohydramnios, } \\
\text { IUGR }\end{array}$ & $\begin{array}{l}\text { Non reactive } \\
\text { Deceleration } \\
\text { present }\end{array}$ & LUCS & $\begin{array}{l}\text { Birth weight } \\
1.2 \mathrm{~kg}, \mathrm{SGA} \\
\text { with prematurity }\end{array}$ \\
\hline 5 & $\begin{array}{l}\text { Neonatal } \\
\text { death at } \\
3^{\text {rd }} \text { day }\end{array}$ & 34 & $\begin{array}{l}\text { Pre eclampsia } \\
\text { with DM }\end{array}$ & $\begin{array}{l}\text { Non reactive } \\
\text { Reduced bear to } \\
\text { beat variability } \\
\text { Deceleration present }\end{array}$ & LUCS & $\begin{array}{l}\text { Birth weight } \\
4 \mathrm{~kg}, \mathrm{RDS} .\end{array}$ \\
\hline 6 & $\begin{array}{l}\text { Neonatal } \\
\text { death at } \\
3^{\text {rd }} \text { day }\end{array}$ & 34 & $\begin{array}{l}\text { Oligohydramnios, } \\
\text { IUGR }\end{array}$ & $\begin{array}{l}\text { Non reactive } \\
\text { Deceleration } \\
\text { present }\end{array}$ & LUCS & $\begin{array}{l}\text { Birth weight } \\
1.1 \mathrm{~kg}, \mathrm{SGA} \\
\text { with prematurity }\end{array}$ \\
\hline
\end{tabular}




\section{Discussion:}

The goal of the obstetrician and neonatology is not only to prevent fetal death by taking care of pregnent women but also to detect fetal compromise and to monitor timely delivery of such infant. ${ }^{7}$ Seventy to ninety percent of fetal deaths occurred before the onset of labour. ${ }^{7}$ A number of intra partum fetal deaths occur among compromised fetus which can not tolerate the stress of the labour and succumb.

Although technology has made great advances in the field of antepartum fetal surveillance and intrapartum monitoring, obstetricians should be aware of the limitation of these methods. ${ }^{11}$ The diagnosis of fetal distress during labour cannot be assessed by any single clinical or laboratory measurement. CTG is the most commonly used test for antepartum and intrapartum fetal surveillance in majority hospitals of developed countries although the clinical impact of cardiotocography on neonatal outcome remains controversial ${ }^{1}$. CTG provides direct information of fetal condition in contrast to other technique. The rational behind this test is that it gives an indication via the cerebro-cardiac response of fetal cerebral activity that is modified in the presence of hypoxia. Acceleration of FHR is due to intact responsive CNS mechanism. The loss of FHR variability or decelerations reflects depression of this CNS mechanism. It is not only the result of fetal hypoxia and acidosis; it can be due to fetal sleep, fetal anomalies, sedative and narcotics to mother, which explain healthy outcome of non-reactive CTG. In spite of lack of specificity cardiotocography is a useful procedure for antepartum fetal surveillance and it remains the mainstay of intrapartum fetal assessment ${ }^{11}$. The purpose of this study was to test the ability of a CTG to predict pregnancy outcomes and early neonatal outcomes.

CTG was taken from patients at $>32$ weeks gestation because the likelihood of a non-reactive test is substantially increased early in third trimester. Both Lavin et al ${ }^{12}$ and Druzin et a ${ }^{13}$ have reported that $15 \%$ of NST remain non reactive between 28 and 32 weeks. After 32 weeks, the incidences of reactive and non-reactive tests are comparable to those seen at term and eliminate concern regarding the immature nervous system ${ }^{7}$. Before 27 weeks gestation, the fetal heart response to fetal movement may in fact be a bradycardia ${ }^{7}$.

There was no significant difference between the two CTG groups regarding the maternal age, parity, gravidity and gestational age, which was similar to many published studies such as by Dellinger et al ${ }^{6}$. Both the groups included patients who were relatively elderly and have low parity. Gravidity was higher due to induced abortion or MR and history of repeated pregnancy loss.
Though the mean gestational age of the two CTG groups showed no significant difference, but in abnormal CTG group the frequently observing gestational age was lower than the normal CTG group because of early intervention was taken by observing the abnormal fetal heart rate pattern.

CTG showing only tachycardia had $13.3 \%$ abnormal out comes. It is the early sign of fetal distress ${ }^{7}$. As interventions were taken early outcomes were good. Bradycardia was seen in $4 \%$ case outcome was normal. Druzin et $\mathrm{al}^{14}$, Dashow et $\mathrm{al}^{15}$ in their study observed bradycardia in 1$2 \%$ of all CTG. Druzin et al ${ }^{14}$ defined such bradycardia, a fetal heart rate of 90 beats per minute or a fall in the fetal heart rate of 40 beats per minute below the base line for one minute or longer. Druzin et $\mathrm{al}^{13}$ in his study found that bradycardia was associated with increased morbidity and mortality; the causes were cord compression, IUGR and fetal malformation.

In the current study 50\% tracings with absent beat-to-beat variability showed abnormal outcomes. Studies done by Shields et al ${ }^{16}$ and Langer et $\mathrm{al}^{17}$ demonstrated that the fundamental component of ominous fetal heart rate pattern is absent or markedly decreased FHR variability.

In this study non-reactive CTG were associated with $47.3 \%$ abnormal outcomes which is similar to the studies done by Kubli et al ${ }^{18}$, Schifrin et al ${ }^{19}$ Keogen et al ${ }^{20}$, Flynn et $\mathrm{al}^{21}$.

CTG showing decelerations were associated with $84.2 \%$ abnormal outcomes. In this study deceleration included spontaneous decelerations in antepartum CTG, moderate to severe variable decelerations and late decelerations. In most cases associated with reduced baseline variability and basal fetal heart rate abnormality.

When the risk factors are more the over all outcomes are more among the abnormal CTG group ${ }^{17}$. In this study it was seen that when diabetic patients developed preeclampsia, intrauterine growth retardation, oligohydramnios, abnormal outcomes were more and risk factors are interrelated, one predispose to others.

In respect to mode of delivery, there was a high incidence of caesarean section in this study. The reason for high incidence of caesarean section in this study in spite of normal test result was due to obstetrical indications, like history of previous caesarean section, cephalopelvic disproportion, severe preeclampsia and severe intrauterine growth retardation. Here caesarean delivery for fetal distress was significantly higher in abnormal CTG group, this finding is similar to the observation of Dellinger et $\mathrm{al}^{6}$. 
Reduced liquor volume before labour is considered an indication of placental insufficiency and reduced liquor volume during labour is associated with an increased incidence of FHR decelerations and may reduce the volume of the intervillous space and may predispose to umbilical cord occlusion, which increase the risk of fetal hypoxemia. In the past, the presence of meconium in the amniotic fluid was considered to be a sign of fetal hypoxia.

In the study Apgar score was $<7$ at $1 \mathrm{~min}$ among the babies of abnormal CTG group than normal CTG that was similar to the study done by Dellinger et $\mathrm{al}^{6}$. The difference in number of the babies with Apgar score $<7$ at 5 min was very insignificant in normal CTG group than abnormal CTG group which was similar to many other studies.

Apgar scoring has been the conventional means of evaluating the status of the infant at birth. It is usually assumed that this score reflects the degree of neonatal asphyxia. However recent studies ${ }^{17}$ using cord blood analysis and fetal scalp blood $\mathrm{pH}$ have cast serious doubts on the reliability of Apgar scoring for asphyxia. An analysis of several published works on the subject gives the following approximate indexes of accuracy for the Apgar score in the prediction of hypoxemia: sensitivity $47 \%$, specificity $89 \%$, positive predictive value $56 \%$, negative predictive value $86 \%^{22}$.

In the present study no perinatal death was observed in normal CTG group. In abnormal CTG group rate was 60 per 1000 total birth, which was similar to some other studies. Perinatal mortality (PNM) among total study population $(n=200)$ was 30 per 1000 .

The PNM rate in the present study was significantly lower than the PNM in other teaching centers of Bangladesh. Timely intervention according to CTG results may be the reasons for such variation.

The study did not attempt to demonstrate an ability to decrease caesarean delivery rates, nor did it attempt to link electronic fetal monitoring with long term neurologic function and cerebral palsy. It only attempted to show the pregnancy outcome and early neonatal outcomes in case of normal and abnormal CTG cases.

\section{Conclusion:}

The present study showed that the mean Apgar score was low among the babies with mothers having abnormal than normal CTG. The proportion of immediate resuscitation and admission of the babies at neonatal care unit was higher among this group. Perinatal death was also significantly higher in this group. Thus overall outcome was better in normal CTG group. On the other hand the perinatal mortality (PNM) in the present study was significantly lower than the PNM of Bangladesh. Timely intervention according to CTG results may be the reasons for such variation. Many neonates in abnormal CTG group were not asphyxiated at birth. So CTG can be continued as a good screening test of fetal surveillance but it is not the sole criteria to influence the management of high-risk pregnancies. CTG should be supplemented with other test like biophysical profile and fetal scalp $\mathrm{pH}$ before intervention.

\section{References:}

1. Parer JT, King T. Foetal heart rate monitoring : Is it salvageable? Am J Obs Gynecol 2000; 182: 982-7.

2. Low JA, Killen H, Derrick EJ. The prediction and prevention of intrapartum fetal asphyxia in pre term pregnancies. Am J Obs Gynecol 2002; 186: 279-82.

3. Vintzileous AM, Nochimson DJ, Antsaklis A. Comparison of intrapartum electronic fetal heart rate monitoring versus intermittent auscultation in detecting fetal acidemia at birth. Am J Obs Gynecol 1995; 173: 1021-24.

4. Lagrew DC. The Contraction Stress Test. Clinical Obstetrics and Gynecology 1995; 38: 11-25.

5. Mandruzzato G, Meir YJ, Ottavio GD. Computerised evaluation of fetal heart rate in post-term fetuses: long term variation. $\mathrm{Br} \mathrm{J}$ Obs Gynecol 1998; 105: 356-359.

6. Dellinger EH, Boehm FH, Crane MM. Electronic fetal rate monitoring: Early neonatal outcomes associated with normal rate, fetal stress, and fetal distress. Am J Obs Gynecol 2000; 182: 214 $-20$.

7. Gabbe SG, Niebyl JR, Simpson JL. Obstetrics, normal and problems pregnancies. $3^{\text {rd }}$ ed. London: British Willa Pvt. Ltd.; 1999. 678-679: PP 327-329, 339, 403, 404.

8. Schneider E P, Hutson J M, Petric RH: An assessment of the first decades experience with antepartum foetal heart rate testing. Am J Perinatol 1988; 5: 134.

9. Yeh SY, Diaz F, Paul RH. Ten year experience of intrapartum foetal monitoring in LOS Angeles County/University of Southern California Medical Centre. Am J Obs Gynecol 1982; 143: 496500 .

10. Decherney AH, Nathan L . Method of Assessment for pregnancy at Risk. Current Obstet \& Gynaecol. Ninth ed. Now York: McGrawHill Comparies; 2003. 271: PP 261-71.

11. Krishna U, Tank DK, Daftari S. Pregnancy at Risk: Current concepts. Third ed. New Delhi: Japee Brothers Medical Publisbher's Pvt. Ltd.; 2001. 179. pp 182.

12. Lavin J Miodovnik M, Barden T: Relationship of non stress test reactivity and gestational age. Obstet Gynecol: 1984; 63: 338. 
13. Druzin ML, Fox A, Koght E. The relationship of the non stress test to gestational age. Am J Obs Gynecol 1985; 153: 386.

14. Druzin M, Gratacos J, Keegan K. Antepartum fetal heart rate testing. The significance of fetal bradycardia Am J Obstet Gynecol 1981; 139: 194.

15. Dashow E, Read J. Significant fetal bradycardia during antepartum heart rate testing. Am J Obs Gynecol 1984; 145: 187.

16. Shields JR, Schifrin BS. Perinatal antecedents of cerebral palsy. Obst Gynecol 1988; 71: 899-905.

17. Langer O, Vega-Rich M, Cohess W: Terminal pattern: characteristics and management. Am J Perinatol 1985; 2: 300-304.
18. Kubli J. Antepartum foetal heart rate monitoring and ultrasound in obstetrics. In: Beard RW, Cambell S, editors. RCOG scientific meeting. Chicago: Kamyce Company; 2004. pp 342-344.

19. Schifrin BS. Routine foetal heart rate monitoring in the antepartum period. Obs Gynecol 1979; 54: 21-25.

20. Keagen KA, Paul RH. Antepartum foetal heart rate monitoring: non-stress test a primary approach. Am. J. Obs Gynecol. 1980; 136: $75-80$.

21. Flynn AM. A randomized controlled trait of non-stress antepartum cardiotocography. Br. J. Obs Gynecol 1982; 89: 427-433.

22. Arias F. Practical guide to high-risk pregnancy and delivery. 2nd ed. New Delhi: Elsevier India Pvt. Ltd. 2005; 418, 423. pp418,423 . 